\title{
Increased recurrent risk did not improve cerebrovascular disease survivors' response to stroke in China: a cross-sectional, community-based study
}

Shengde Li ${ }^{1}$, Li-Ying Cui ${ }^{1}$, Craig Anderson ${ }^{2,3}$, Chunpeng Gao ${ }^{4}$, Chengdong Yu ${ }^{5}$, Guangliang Shan ${ }^{5}$, Longde Wang ${ }^{6}$, Bin Peng ${ }^{1 *}$ and on behalf of the FAST-RIGHT Investigators and Coordinators

\begin{abstract}
Background: Cerebrovascular disease (CVD) survivors are at a high risk of recurrent stroke. Although it is thought that survivors with higher risk of stroke respond better to stroke onset, to date, no study has been able to demonstrate that. Thus, we investigated whether the intent to call emergency medical services (EMS) increased with recurrent stroke risk among CVD survivors.

Methods: A cross-sectional community-based survey was conducted from January 2017 to May 2017, including 187,723 adults (age $\geq 40$ years) across 69 administrative areas in China. A CVD survivor population of 6290 was analyzed. According to the stroke risk score based on Essen Stroke Risk Score, CVD survivors were divided into three subgroups: low (0), middle (1-3) and high (4-7) recurrent risk groups. Multivariable logistic regression models were used to identify the association between the stroke risk and stroke recognition, as well as stroke risk and EMS calling.

Results: The estimated stroke recognition rate in CVD survivors with low, middle, and high risk was 89.0\% (503/ 565), 85.2\% (3841/4509), and 82.5\% (1001/1213), respectively, while the rate of calling EMS was $66.7 \%$ (377/565), 64.3\% (2897/4509), and 69.3\% (840/1213), respectively. The CVD survivors' knowledge of recognizing stroke and intent to call EMS did not improve with recurrent stroke risk, even after adjustment for multiple socio-demographic factors.

Conclusions: Despite being at a higher risk of recurrent stroke, Chinese CVD survivors showed poor knowledge of stroke, and their intent to call EMS did not increase with recurrent stroke risk. Enhanced and stroke risk-orientated education on stroke recognition and proper response is needed for all CVD survivors.
\end{abstract}

Keywords: Health knowledge, attitudes, practice, Awareness, Emergency medical services, Cerebrovascular disease, Survivors, Risk factors

\footnotetext{
* Correspondence: pengbin3@hotmail.com

'Department of Neurology, Peking Union Medical College Hospital, Peking

Union Medical College and Chinese Academy of Medical Sciences,

Shuaifuyuan1, Dong Cheng District, Beijing 100730, China

Full list of author information is available at the end of the article
}

(c) The Author(s). 2020 Open Access This article is licensed under a Creative Commons Attribution 4.0 International License, which permits use, sharing, adaptation, distribution and reproduction in any medium or format, as long as you give appropriate credit to the original author(s) and the source, provide a link to the Creative Commons licence, and indicate if changes were made. The images or other third party material in this article are included in the article's Creative Commons licence, unless indicated otherwise in a credit line to the material. If material is not included in the article's Creative Commons licence and your intended use is not permitted by statutory regulation or exceeds the permitted use, you will need to obtain permission directly from the copyright holder. To view a copy of this licence, visit http://creativecommons.org/licenses/by/4.0/ The Creative Commons Public Domain Dedication waiver (http://creativecommons.org/publicdomain/zero/1.0/) applies to the data made available in this article, unless otherwise stated in a credit line to the data. 


\section{Background}

In China, as in many countries, stroke is a major health challenge, with an increasing number of stroke-related deaths and disabilities [1-4]. Reperfusion therapy with intravenous alteplase, can improve the outcomes of acute ischemic stroke (AIS). However, less than $2 \%$ of AIS Chinese patients receive alteplase primarily due to pre-hospital delays $[5,6]$. Emergency medical services (EMS) usage provides quick access to hospitals, however, a very low proportion of AIS patients use EMS in China [6-9]. Survivors of CVD are at higher risk of severe stroke [1013]. In China, common vascular risk factors such as hypertension, diabetes and dyslipidemia are not well adequately managed [14-16], and many of them are oblivious to their stroke risk factors [17]. Thus, EMS seems more important to patients with higher recurrent risk of stroke. However, previous study reported that a significant ratio of $34.6 \%$ of Chinese CVD survivors did not call EMS [18]. The details on stroke recognition and responses among CVD survivors remained unclear. Therefore, based on the FASTRIGHT study, we aimed to determine the characteristics of CVD survivors, and whether the intent to call EMS increased with the recurrent stroke risk.

\section{Methods}

Data were obtained from the FAST-RIGHT study, part of the China National Stroke Screening Survey (CNSSS), and included 69 administrative areas between January 2017 and May 2017. More details on the CNSSS are outlined elsewhere $[18,19]$, and can also be found on the website of the National Health Commission [20]. The CNSSS was a crosssectional community-based survey with a 2-stage stratified sampling framework based on county-level demographic data. In the FAST-RIGHT study, residents aged 40 years and older were screened by trained research staff using a standard face-to-face questionnaire regarding sociodemographic, medical, and family history, lifestyle factors, and four specific questions regarding stroke awareness (See Supplementary Appendix 1, Additional file 1). Commencement of stroke education was also recommended after completing the questionnaire survey. All screening data were transferred from questionnaires to an electronic database and checked centrally for completeness and errors by an experienced data manager. The FAST-RIGHT study was approved by the central ethics committee of Peking Union Medical College Hospital (the principal study center), and all participants provided written informed consent.

\section{Explanatory and outcome variables}

Recognition of stroke symptoms was defined as a participant's unprovoked awareness of "facial droop," "arm weakness," and "speech disturbances" (slurred speech, or word-finding difficulties) [21]. Calling EMS immediately after the onset of any of these symptoms was regarded as the correct action in response to stroke. A reported history of stroke was confirmed by a neurologist or physician. The modifiable risk factors included hypertension, diabetes, dyslipidemia, overweight and obesity $(\mathrm{BMI}=24-50)$, atrial fibrillation $(\mathrm{AF}) /$ valvular heart disease/coronary heart disease/other heart disease, smoking (including current, former, and passive smoking), drinking (including current and former drinking), and limited exercise (See Supplementary Appendix 2, Additional file 1). Survey participants were divided into two subgroups: CVD survivors and non-CVD population. CVD survivors were defined as those with a history of cerebrovascular disease, including ischemic stroke, cerebral hemorrhage, subarachnoid hemorrhage, and transient ischemic attacks. Individuals without a history of cerebral vascular disease were classified as the non-CVD.

\section{Assessment of recurrent stroke risk}

Based on the Essen Stroke Risk Score (ESRS), a stroke risk score was developed with more scores indicating higher stroke risk, including age, hypertension, diabetes, smoking and heart disease. The stroke risk score was divided as three levels: low risk (0), middle risk (1-3) and high risk (4-7) [22, 23] (See Supplementary Appendix 3, Additional file 1).

\section{Statistical analyses}

The stroke recognition rate (SRR) and correct action rate (CAR) of total, low-, middle-, and high-risk groups were determined based on the specific subgroups, which was defined by age, sex, site (urban vs. rural), region, education level, and annual income among CVD survivors. The association between the increased recurrent stroke risk and stroke recognition, as well as calling EMS were analyzed using multivariable logistic regression.

Based on stroke risk score, we compared the sociodemographic factors among the low-, middle- and highrisk groups among CVD survivors. A standard two-sided $P$ value $(<0.05)$ was considered statistically significant. All analyses were performed using SAS version 9.3.

\section{Results}

Of the 187,723 residents screened for eligibility, 6290 were CVD survivors and were included in our analysis (See Supplementary Table S1 and Figure S1, Additional file 1). Stroke risk score showed a U-shaped association with CAR, but negative correlation with SRR. In the low-, middle- and high-risk subgroups, the SRRs were $89.0,85.2$, and $82.5 \%$, respectively $(P=0.0014)$, while CARs were $66.7,64.3$, and $69.3 \%$, respectively $(P=0.004)$ (See Supplementary Table S2, Additional file 1). In total 
Table 1 SRR and CAR by demographic, socio-economic, and stroke risk variables in CVD survivors

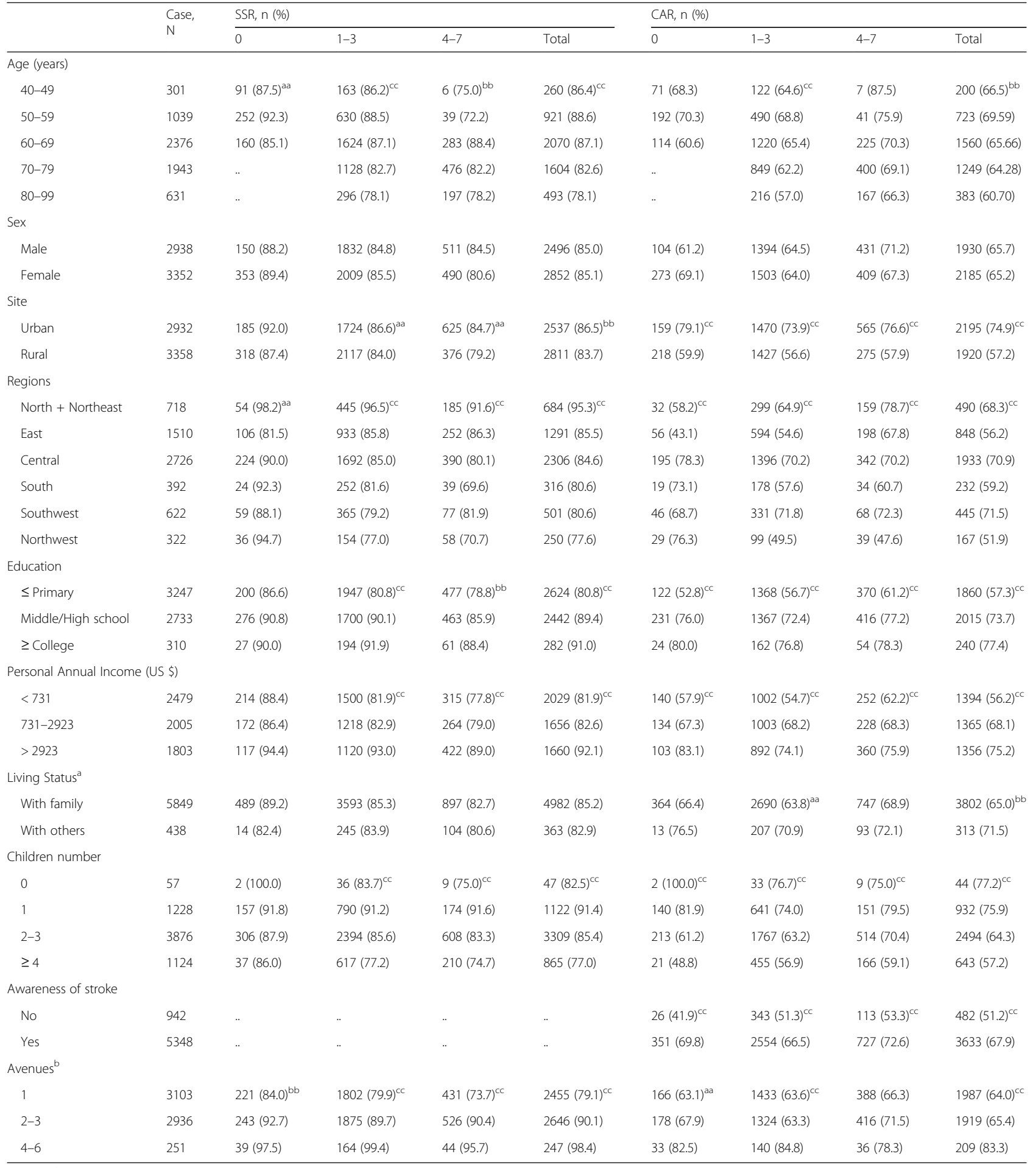

SRR Stroke recognition rate, CAR Correct action rate
Stroke risk score, its range was 0 to 7 and was divided as three subgroups: $0,1-3$, and 4-7

n: number for recognizing stroke/correct action to stroke in each cell; The total number of each cell was shown in Supplementary Table S4 of Additional file 1

aith family includes living with spouse/children; With others includes being single, living in a nursing home, and with other people

${ }^{\mathrm{b}}$ Number of avenues taken to learn about acute stroke

${ }^{\text {aa }} P$ value $<0.05$

${ }^{\mathrm{bb}} P$ value $<0.01$

" $P$ value $<0.001$

Those without superscripts in the first line of every item: $P$ value $\geq 0.05$ 
group and low-, middle- and high-risk subgroups, the estimated SRR and CAR varied across regions and socioeconomic statuses (Table 1). Across most different subgroups, CAR was $5.3-40.0 \%$ lower than SRR. Among those who recognized the onset of a stroke, only $67.9 \%$ intended to call EMS (See Supplementary Table S3, Additional file 1).

The high-risk subgroup was older, and had higher education and income levels (See Supplementary Table S4, Additional file 1). The proportions of family history of stroke (33.6\%) and urban adults $(60.8 \%)$ were significantly higher in high-risk subgroup. Compared with low-risk subgroup, middle- and high-risk CVD survivors had markedly higher prevalence of modifiable cardiovascular risk factors (Fig. 1).

Figures 2 and 3 show the variables independently associated with recognition of stroke symptoms and calling EMS, respectively. The CVD survivors' ability of stroke recognition and intent to call EMS did not improve with increasing stroke risk score. Moreover, out of the multiple factors, only urban-rural sites, region, education, annual income, living status, stroke awareness, number of avenues to learn about stroke, and family history were statistically significant in calling EMS. Greater attempts to learn about stroke were strongly associated with both stroke recognition and prompt calling of EMS. The rate of using Internet-related avenues to gain knowledge of stroke was 9.0\%, which decreased with stroke risk score (20.9\% in low-risk group vs. $6.5 \%$ in high-risk group) (See Supplementary Table S5, Additional file 1).

\section{Discussion}

Our study shows that the knowledge of identifying stroke onset and intent to call EMS in Chinese CVD survivors were very poor and did not increase with recurrent stroke risk. Fortunately, CVD survivors were slightly more aware of the correct stroke response than the non-CVD population (OR: 1.11, 95\% CI: 1.05-1.18) [18]. The rate of intent to call EMS (65.4\%) [18] was almost similar to those previously reported in China [24] (58.5\%), the United States [25] (62.9\%), and Japan [26] (81.2\%), but was significantly higher than the actual EMS usage rate in China (12.5-23.1\%) [6, 8, 9, 27]. However, even in CVD survivors with high stroke risk score, one-third of them would not call EMS at the onset of a recurrent stroke.

Recurrent stroke is usually more devastating to the patient and is associated with higher treatment costs than the first episode [10, 11, 13]. A high prevalence of cardiovascular risk factors among CVD survivors was reported in our study, which accounted for most cases of stroke onset [28]. Multiple risk factors indicated a higher risk of recurrent stroke [28], which seems to be even higher in China due to poor control of these factors

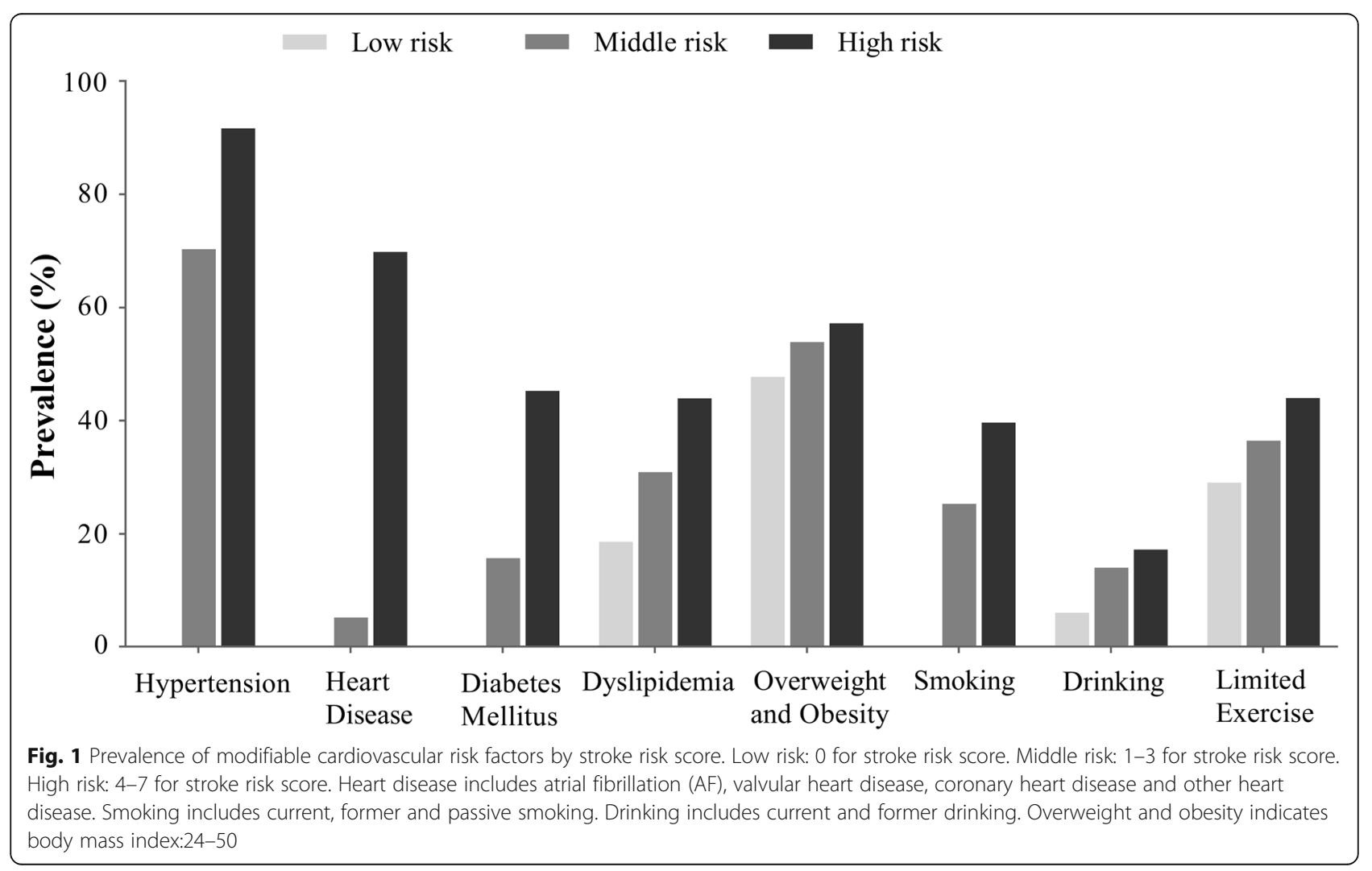




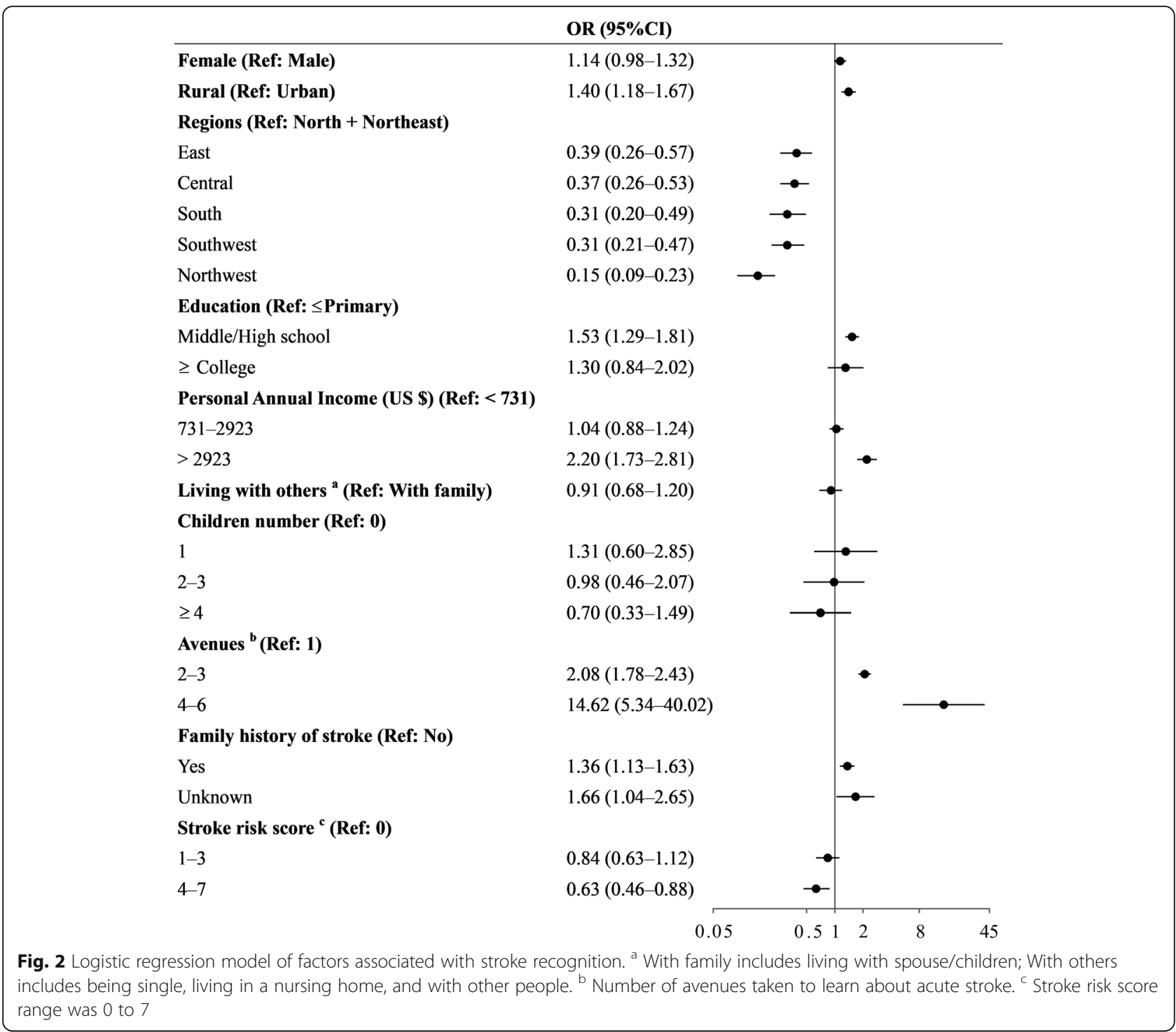

[29-32]. Unfortunately, in our study, higher recurrent stroke risk did not correlate with the intent to call EMS, which may delay access to reperfusion therapy [6, 9, 33]. CVD survivors, even those with high recurrent stroke risk, failed to regard underlying diseases as risk factors of stroke [17, 34, 35], and did not fully understand the danger of cardiovascular risk factors, and were unaware of their situation [17], probably due to poor education on secondary stroke prevention. For those with higher recurrent stroke risk, more intensive education program on risk factors, recurrent stroke recognition, and calling EMS should be implemented.

In contrast to results from the entire population, the odds of calling EMS among the CVD survivors depended only on a few factors, such as the region and annual income [18]. Moreover, contrary to the results from previous studies $[18,36]$, even highly educated
CVD survivors did not perform better at recognizing stroke onset and calling EMS. Therefore, there are underlying factors other than lack of stroke education that remain unclear and require further study. This emphasizes the need to revise our previous programs to educate CVD survivors differently from non-CVD population and optimize secondary preventive programs on the appropriate response to stroke onset. Moreover, the limited number of associated factors that affect the odds of calling EMS among CVD survivors imply that targeted stroke-education programs can be more efficiently designed and conducted for CVD survivors than for the non-CVD population [18].

Low education, low income, and rural location were common among CVD survivors [37], which indicated a lower equity of needs and resource allocation to EMS $[38,39]$ and a poor capacity to curb the stroke burden 


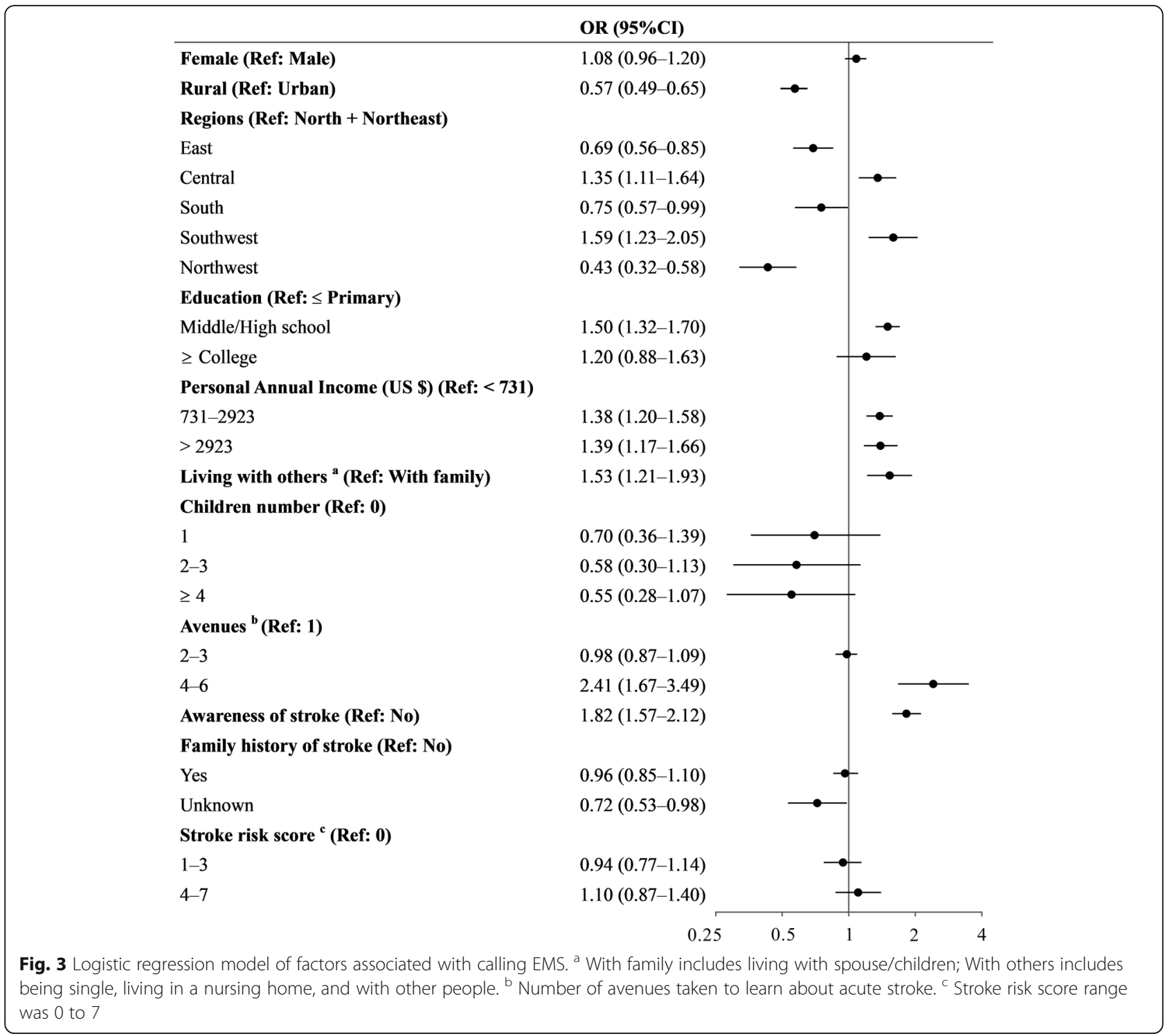

[40, 41]. Additionally, our study demonstrated that only having $\geq 4$ avenues for gaining knowledge on stroke was associated with calling EMS, indicating that the CVD survivors were not sensitive to solitary education campaigns, while multiple avenues showed synergistic effects [26]. Unfortunately, nearly half of CVD survivors with high recurrent risk had only one avenue to learn about stroke. With the availability of point-to-point functions, Internet-related avenues appear to be more appropriate to educate specific groups, but the Internet usage rate was extremely low among Chinese CVD survivors [26, $35,42]$. Finally, since CVD survivors face extremely high prevalence of risk factors, it is better to make them recognize that good control of these modifiable risk factors can reduce stroke risk [28], and that timely and proper response to stroke onset is critical to improving the outcome [36]. Thus, we should consider these unique and unfavorable points when launching education programs for Chinese CVD survivors.

Although ESRS predicts recurrent stroke risk, it could not be applied to our study directly [22]. Our model was partially different from ESRS, which might incur bias in predicting recurrent stroke risk. But, we found that prevalence of modifiable risk factors increased with stroke risk score, which indicated that CVD survivors with high stroke risk score might have highest odds to recurrent stroke [28].

The multistage nonrandom sampling design of this study and the selection from CNSSS was biased, although screening sites in urban and rural areas were selected in a 1:1 ratio [19]. Moreover, the prediction of recurrent stroke risk is complex and includes extensive risk factors. However, we only selected several factors to assess the risk for recurrent stroke. Therefore, the 
influence of other factors remained uninvestigated, such as the stenosis of intracranial artery [43]. Finally, further study is needed for the effect of stroke risk on patients' response to stroke onset, which could optimize our strategy for stroke education.

\section{Conclusions}

Our study found that stroke recognition and intent to call EMS in response to stroke-related symptoms were low among Chinese CVD survivors, and did not improve with stroke risk. CVD survivors had various recurrent stroke risks, but showed similar knowledge of stroke. Enhanced stroke education on stroke recognition and proper response should be made according to recurrent stroke risk of CVD survivors.

\section{Supplementary information}

Supplementary information accompanies this paper at https://doi.org/10. 1186/s12883-020-01724-1.

\section{Additional file 1.}

\section{Abbreviations}

AF: Atrial fibrillation; AIS: Acute ischemic stroke; BMI: Body mass index; CAR: Correct action rate; CVD: Cerebrovascular disease; CNSSS: China National Stroke Screening Survey; Cl: Confidence interval; EMS: Emergency medical services; ESRS: Essen Stroke Risk Score; OR: Odds ratio; SRR: Stroke recognition rate

\section{Acknowledgements}

We thank Baohua Chao, Lei Cao, Lingxiao Wang, and their team for important support in the undertaking of this program.

\author{
Authors' contributions \\ $B P, L W$, and LYC designed the study. SL, CY, GS, and BP analyzed the data. \\ CG finished data collection and management. SL wrote the paper. LYC, BP, \\ and $C A$ revised the paper. All authors have read and approved the \\ manuscript.
}

\section{Funding}

This study was funded by the Ministry of Finance of the People's Republic of China (Issued by Finance and Social Security [2016] Document No.50, Ministry of Finance). The sponsor of the study had no role in study design, data collection, data analysis, data interpretation, or writing of the article.

\section{Availability of data and materials}

The data sets in this study are available from the corresponding author on reasonable request.

\section{Ethics approval and consent to participate}

The FAST-RIGHT study was approved by the central ethics committee of Peking Union Medical College Hospital (the principal study center), and all participants provided written informed consent.

\section{Consent for publication}

Not applicable.

\section{Competing interests}

Craig Anderson is employed by The George Institute China and has a National Health and Medical Research Council (NHMRC) of Australia grant. $\mathrm{He}$ is also a consultant for Takeda China and Amgen. The other authors declared no potential conflicts of interest.

\section{Author details}

${ }^{1}$ Department of Neurology, Peking Union Medical College Hospital, Peking Union Medical College and Chinese Academy of Medical Sciences, Shuaifuyuan1, Dong Cheng District, Beijing 100730, China. ${ }^{2}$ Neurological and Mental Health Division, The George Institute for Global Health, Faculty of Medicine, University of New South Wales, Sydney, Australia. ${ }^{3}$ The George Institute for Global Health, Peking University Health Science Center, Beijing China. ${ }^{4}$ Disease Control and Prevention Office, Dalian Municipal Central Hospital, Dalian, Liaoning, China. ${ }^{5}$ Department of Epidemiology and Statistics, Institute of Basic Medical Sciences, Chinese Academy of Medical Sciences, Beijing, China. ${ }^{6}$ Stroke Control Project Committee, The National Health Commission, Beijing, China.

Received: 12 September 2019 Accepted: 12 April 2020

Published online: 21 April 2020

\section{References}

1. Feigin $\mathrm{VL}$, Forouzanfar MH, Krishnamurthi R, Mensah GA, Connor M, Bennett DA, et al. Global and regional burden of stroke during 1990-2010: findings from the global burden of disease study 2010. Lancet. 2014;383(9913):24554.

2. Liu M, Wu B, Wang WZ, Lee LM, Zhang SH, Kong LZ. Stroke in China: epidemiology, prevention, and management strategies. Lancet Neurol. 2007; 6(5):456-64. https://doi.org/10.1016/S1474-4422(07)70004-2

3. Yang G, Wang Y, Zeng Y, Gao GF, Liang X, Zhou M, et al. Rapid health transition in China, 1990-2010: findings from the global burden of disease study 2010. Lancet. 2013;381(9882):1987-2015. https://doi.org/10.1016/ S0140-6736(13)61097-1.

4. de Graaf JA, van Mierlo ML, Post MWM, Achterberg WP, Kappelle LJ, VisserMeily JMA. Long-term restrictions in participation in stroke survivors under and over 70 years of age. Disabil Rehabil. 2018;40(6):637-45. https://doi.org/ 10.1080/09638288.2016.1271466.

5. Wang Y, Liao X, Zhao X, Wang DZ, Wang C, Nguyen-Huynh MN, et al. Using recombinant tissue plasminogen activator to treat acute ischemic stroke in China: analysis of the results from the Chinese National Stroke Registry (CNSR). Stroke. 2011;42(6):1658-64. https://doi.org/10.1161/STROKEAHA.110. 604249

6. Jin H, Zhu S, Wei JW, Wang J, Liu M, Wu Y, et al. Factors associated with prehospital delays in the presentation of acute stroke in urban China. Stroke. 2012;43(2):362-70. https://doi.org/10.1161/STROKEAHA.111.623512.

7. Saver JL, Smith EE, Fonarow GC, Reeves MJ, Zhao X, Olson DM, et al. The "golden hour" and acute brain ischemia: presenting features and lytic therapy in $>30,000$ patients arriving within 60 minutes of stroke onset. Stroke. 2010;41(7):1431-9. https://doi.org/10.1161/STROKEAHA.110.583815.

8. Jiang B, Ru X, Sun H, Liu H, Sun D, Liu Y, et al. Pre-hospital delay and its associated factors in first-ever stroke registered in communities from three cities in China. Sci Rep. 2016;6:29795. https://doi.org/10.1038/srep29795.

9. Yin X, Yang T, Gong Y, Zhou Y, Li W, Song X, et al. Determinants of emergency medical services utilization among acute ischemic stroke patients in Hubei Province in China. Stroke. 2016;47(3):891-4. https://doi. org/10.1161/STROKEAHA.115.011877.

10. Amarenco P, Lavallee PC, Monteiro Tavares L, Labreuche J, Albers GW, Abboud $\mathrm{H}$, et al. Five-year risk of stroke after TIA or minor ischemic stroke. N Engl J Med. 2018;378(23):2182-90. https://doi.org/10.1056/ NEJMoa1802712.

11. Hankey GJ. Secondary stroke prevention. Lancet Neurol. 2014;13(2):178-94. https://doi.org/10.1016/S1474-4422(13)70255-2.

12. Luengo-Fernandez R, Gray AM, Rothwell PM, Oxford VS. A population-based study of hospital care costs during 5 years after transient ischemic attack and stroke. Stroke. 2012;43(12):3343-51. https://doi.org/10.1161/STROKEAHA. 112.667204

13. Wang YL, Pan YS, Zhao XQ, Wang D, Johnston SC, Liu LP, et al. Recurrent stroke was associated with poor quality of life in patients with transient ischemic attack or minor stroke: finding from the CHANCE trial. CNS Neurosci Ther. 2014;20(12):1029-35. https://doi.org/10.1111/cns.12329.

14. Pan $L$, Yang $Z, W u Y$, Yin $R X$, Liao $Y$, Wang J, et al. The prevalence, awareness, treatment and control of dyslipidemia among adults in China. Atherosclerosis. 2016;248:2-9. https://doi.org/10.1016/j.atherosclerosis.2016. 02.006.

15. Lu J, Lu Y, Wang X, Li X, Linderman GC, Wu C, et al. Prevalence, awareness, treatment, and control of hypertension in China: data from 1.7 million 
adults in a population-based screening study (China PEACE Million Persons Project). Lancet. 2017;390(10112):2549-58. https://doi.org/10.1016/S01406736(17)32478-9

16. Qin Y, Wang R, Ma X, Zhao Y, Lu J, Wu C, et al. Prevalence, awareness, treatment and control of diabetes mellitus-a population based study in Shanghai, China. Int J Environ Res Public Health. 2016;13:5. https://doi.org/ 10.3390/ijerph13050512.

17. Wang MD, Wang Y, Mao L, Xia YP, He QW, Lu ZX, et al. Acute stroke patients' knowledge of stroke at discharge in China: a cross-sectional study. Tropical Med Int Health. 2018;23(11):1200-6. https://doi.org/10.1111/tmi. 13148.

18. Li S, Cui LY, Anderson C, Zhu S, Xu P, Wei T, et al. Public awareness of stroke and the appropriate responses in China: a cross-sectional community-based study (FAST-RIGHT). Stroke. 2019;50:455-62. https://doi. org/10.1161/ST ROKEAHA.118.023317.

19. Longde $W$, Ling $Y$, Yang $H, Y i Z$, Yongjun W, Xunming J, et al. Fixed-dose combination treatment after stroke for secondary prevention in China: a national community-based study. Stroke. 2015;46(5):1295-300. https://doi. org/10.1161/STROKEAHA.114.007384.

20. National Center for Stroke Control and Prevention, National Health Commission. The China National Stroke Screening Survey Guidelines [online, in Chinese]. 2016, http://cnstroke.com/WebManage/InterveneProject/Index. (Accessed 28 May 2019).

21. Harbison J, Hossain O, Jenkinson D, Davis J, Louw SJ, Ford GA. Diagnostic accuracy of stroke referrals from primary care, emergency room physicians, and ambulance staff using the face arm speech test. Stroke. 2003;34(1):71-6.

22. Meng X, Wang Y, Zhao X, Wang C, Li H, Liu L, et al. Validation of the Essen stroke risk score and the stroke prognosis instrument II in Chinese patients. Stroke. 2011;42(12):3619-20. https://doi.org/10.1161/STROKEAHA.111.624148.

23. Weimar C, Diener HC, Alberts MJ, Steg PG, Bhatt DL, Wilson PW, et al. The Essen stroke risk score predicts recurrent cardiovascular events: a validation within the REduction of Atherothrombosis for continued health (REACH) registry. Stroke. 2009;40(2):350-4. https://doi.org/10.1161/STROKEAHA.108. 521419

24. Yang J, Zheng M, Cheng S, Ou S, Zhang J, Wang N, et al. Knowledge of stroke symptoms and treatment among community residents in Western urban China. J Stroke Cerebrovasc Dis. 2014;23(5):1216-24. https://doi.org/ 10.1016/j.jstrokecere brovasdis.2013.10.019.

25. Fussman C, Rafferty AP, Lyon-Callo S, Morgenstern LB, Reeves MJ. Lack of association between stroke symptom knowledge and intent to call 911: a population-based survey. Stroke. 2010;41(7):1501-7. https://doi.org/10.1161/ STROKEAHA.110.578195.

26. Miyamatsu N, Okamura T, Nakayama H, Toyoda K, Suzuki K, Toyota A, et al. Public awareness of early symptoms of stroke and information sources about stroke among the general Japanese population: the Acquisition of Stroke Knowledge Study. Cerebrovasc Dis. 2013;35(3):241-9. https://doi.org/ 10.1159/000347066.

27. Gu HQ, Rao ZZ, Yang X, Wang CJ, Zhao XQ, Wang YL, et al. Use of emergency medical services and timely treatment among ischemic stroke. Stroke. 2019:50(4):1013-6. https://doi.org/10.1161/STROKEAHA.118.024232.

28. O'Donnell MJ, Chin SL, Rangarajan S, Xavier D, Liu L, Zhang H, et al. Global and regional effects of potentially modifiable risk factors associated with acute stroke in 32 countries (INTERSTROKE): a case-control study. Lancet. 2016;388(10046):761-75. https://doi.org/10.1016/S0140-6736(16)30506-2.

29. Wei Y, Xu J, Wu H, Zhou G, Chen S, Wang C, et al. Survey of Antithrombotic Treatment in Rural Patients (>60 years) with Atrial Fibrillation in East China. Sci Rep. 2018;8(1):6830. https://doi.org/10.1038/s41598-018-24878-y.

30. Yang F, Qian D, Chen J, Hu D, Hou M, Chen S, et al. Prevalence, awareness, treatment and control of diabetes mellitus in rural China: results from Shandong Province. Diabet Med. 2016;33(4):454-8. https:/doi.org/10.1111/dme.12842.

31. Zhao Y, Yan H, Marshall RJ, Dang S, Yang R, Li Q, et al. Trends in population blood pressure and prevalence, awareness, treatment, and control of hypertension among middle-aged and older adults in a rural area of Northwest China from 1982 to 2010. PLoS One. 2013;8(4):e61779. https:// doi.org/10.1371/journal.pone.0061779.

32. Chen Z, Peto $R$, Zhou $M$, lona $A$, Smith $M$, Yang $L$, et al. Contrasting male and female trends in tobacco-attributed mortality in China: evidence from successive nationwide prospective cohort studies. Lancet. 2015;386(10002): 1447-56. https://doi.org/10.1016/S0140-6736(15)00340-2.

33. Fonarow GC, Smith EE, Saver JL, Reeves MJ, Bhatt DL, Grau-Sepulveda MV et al. Timeliness of tissue-type plasminogen activator therapy in acute ischemic stroke: patient characteristics, hospital factors, and outcomes associated with door-to-needle times within 60 minutes. Circulation. 2011 123(7):750-8. https://doi.org/10.1161/CIRCULATIONAHA.110.974675.

34. Das K, Mondal GP, Dutta AK, Mukherjee B, Mukherjee BB. Awareness of warning symptoms and risk factors of stroke in the general population and in survivors stroke. J Clin Neurosci. 2007;14(1):12-6. https://doi.org/10.1016/j. jocn.2005.12.049.

35. Metias MM, Eisenberg N, Clemente MD, Wooster EM, Dueck AD, Wooster $D L$, et al. Public health campaigns and their effect on stroke knowledge in a high-risk urban population: a five-year study. Vascular. 2017;25(5):497-503. https://doi.org/10.1177/1708538117691879.

36. Fassbender K, Balucani C, Walter S, Levine SR, Haass A, Grotta J. Streamlining of prehospital stroke management: the golden hour. Lancet Neurol. 2013; 12(6):585-96. https://doi.org/10.1016/S1474-4422(13)70100-5.

37. Wang $W$, Jiang $B$, Sun $H$, Ru X, Sun D, Wang $L$, et al. Prevalence, incidence, and mortality of stroke in China: results from a Nationwide populationbased survey of 480687 adults. Circulation. 2017;135(8):759-71. https://doi. org/10.1161/CIRCULATIONAHA.116.025250.

38. Liu Y, Jiang Y, Tang S, Qiu J, Zhong X, Wang Y. Analysis of the equity of emergency medical services: a cross-sectional survey in Chongqing city. Int J Equity Health. 2015;14:150. https://doi.org/10.1186/s12939-015-0282-8.

39. Yan K, Jiang Y, Qiu J, Zhong X, Wang Y, Deng J, et al. The equity of China's emergency medical services from 2010-2014. Int J Equity Health. 2017;16(1): 10. https://doi.org/10.1186/s12939-016-0507-5.

40. Pan Y, Song T, Chen R, Li H, Zhao X, Liu L, et al. Socioeconomic deprivation and mortality in people after ischemic stroke: the China National Stroke Registry. Int J Stroke. 2016;11(5):557-64. https://doi.org/10.1177/ 1747493016641121

41. Cha JK, Lim JH, Kim DH, Nah HW, Park HS, Choi JH, et al. Prognostic factors for long-term poor outcomes after acute ischemic stroke in very old age (>80 years) patients: Total cholesterol level might differently influence longterm outcomes after acute ischemic stroke at ages above 80 years. Geriatr Gerontol Int. 2015;15(11):1227-33. https://doi.org/10.1111/ggi.12419.

42. Kim YS, Park SS, Bae HJ, Heo JH, Kwon SU, Lee BC, et al. Public awareness of stroke in Korea: a population-based national survey. Stroke. 2012:43(4):11469. https://doi.org/10.1161/STROKEAHA.111.638460.

43. Powers WJ, Rabinstein AA, Ackerson T, Adeoye OM, Bambakidis NC, Becker K, et al. 2018 guidelines for the early Management of Patients with Acute Ischemic Stroke: a guideline for healthcare professionals from the American Heart Association/American Stroke Association. Stroke. 2018;49(3):e46-e110. https://doi.org/10.1161/STR.0000000000000158.

\section{Publisher's Note}

Springer Nature remains neutral with regard to jurisdictional claims in published maps and institutional affiliations.

Ready to submit your research? Choose BMC and benefit from:

- fast, convenient online submission

- thorough peer review by experienced researchers in your field

- rapid publication on acceptance

- support for research data, including large and complex data types

- gold Open Access which fosters wider collaboration and increased citations

- maximum visibility for your research: over $100 \mathrm{M}$ website views per year

At $\mathrm{BMC}$, research is always in progress.

Learn more biomedcentral.com/submissions 